\title{
Self-Reported Prevalence and Socio-Demographic Determinants of Multiple Parasitic Infection among Schooling Adolescents in Nigeria
}

\author{
Jephtha C. Nmor ${ }^{1,2^{*}}$, Judith Nmor ${ }^{3}$, Prosper Omah ${ }^{2}$, Nwaka H. Kehi' ${ }^{2}$, Kensuke Goto ${ }^{4}$, \\ Junko Toyosawa1, Daisuke Fujita ${ }^{*}$ \\ ${ }^{1}$ National Mental Support Center for School Crisis, Osaka Kyoiku University, Osaka, Japan \\ ${ }^{2}$ Department of Animal and Environmental Biology, Delta State University, Abraka, Nigeria \\ ${ }^{3}$ Department of Nutrition Sciences, Siebold University, Nagasaki, Japan \\ ${ }^{4}$ Department of Eco-Epidemiology, Institute of Tropical Medicine (NEKKEN), Nagasaki University, \\ Nagasaki, Japan \\ Email: ${ }^{*}$ ujjitad@cc.osaka-kyoiku.ac.jp, ${ }^{*}$ icnmor@yahoo.com
}

Received 9 December 2013; revised 9 January 2014; accepted 16 January 2014

Copyright $@ 2014$ by authors and Scientific Research Publishing Inc.

This work is licensed under the Creative Commons Attribution International License (CC BY).

http://creativecommons.org/licenses/by/4.0/

(c) (i) Open Access

\section{Abstract}

Background: Despite the rising burden of parasitic infections among young schooling adolescents in sub-Saharan Africa, insufficient attention has been paid to school-health. This study examined the self-reported prevalence of major parasitic infections and its association with key socio-demographic factors among young schooling adolescents in Southern Nigeria. Methods: An interviewer-administered school-based survey of students attending schools in Southern Nigeria was conducted in 2013 . The study sample involved 585 students $(60.9 \%$ male, $39.2 \%$ female and overall mean age of 15 years). The outcome variable was the self-reported presence of parasitic infection suffered within the past twelve months. The exposure variables were socio-demographic characteristics: age, sex, geolocality, school ownership, parents' level of education and occupation. Association between the number of parasitic infections and socio-demographic factors were examined, and multivariate logistic regression was used to determine socio-demographic factors predictive of the presence of parasitic infections. Results: The most prevalent parasitic diseases reported across the sample were malaria (46.9\%) and helminthiasis $(27.7 \%)$. Over a quarter $(38.5 \%)$ had one infectious disease, while about half $(\mathbf{4 0 . 3 \% )}$ ) reported had more than two infectious diseases. In the study sample, the number of parasitic diseases differed significantly by sex $(p=0.0344)$, age

\footnotetext{
*Corresponding Author.
} 
$(p=0.0483)$, geolocality $(p=0.0001)$, school ownership $(p=0.0012)$ and parents' occupation $(p=$ 0.0199). Multivariate logistic regression analysis showed that attending private school was negatively associated with the presence of parasitic diseases $(\beta=-0.9129, p=0.0022)$. Conclusion: The high prevalence of multiple parasitic infections among the study population is worrisome and should be considered as a school-health concern. Concerted efforts are highly needed to develop school-health intervention programs for addressing the high prevalence of parasitic infection among students. Such programs should be tailored for specific socio-demographic groups. Although there was strong proportionality between self-reported symptoms and parasitic diseases reported, laboratory-based investigation is needed to validate our findings.

\section{Keywords}

\section{Parasitic Diseases; Socio-Demographic Factors; Students; Nigeria; Africa}

\section{Introduction}

Globally, millions of people suffer from parasitic infections. More than 1.2 billion people are infected with chronic soil-transmitted helminths, and 200 million are infected with schistosomiasis [1] [2], 243 million with malaria [3], and 2.5 million with giardiasis [4]. In the tropical countries, especially in Africa, parasitic infections are the major public health problem, and the high prevalence of parasitic infections remains one of the principal factors contributing to children morbidity and mortality [5]. The adverse effects of parasitic infections among children are diverse and alarming. Intestinal parasitic infections have detrimental effects on survival, appetite, growth, school attendance and cognitive performance of school-age children [5] [6].

Parasitic infections are modulated by behavioral, biological, environmental, socioeconomic and health systems factors. Local conditions such as quality of domestic and village infrastructure; economic factors such as monthly income, employment and occupation; and social factors such as education, influence the risk of infection, disease transmission and associated morbidity and mortality [7] [8]. In many parts of the developing world, children are one of the groups at high-risk for parasitic infections [5].

Despite the huge burden of parasitic infection among school children, there are few policies and programs to combat morbidity in school-age children in developing countries, especially when compared with programs for infants and pre-school children, and they could be considered as a neglected group [9]. Moestue et al. [10] identified scarcity of information on the extent and causes of ill-health among school-age children as the principal factor. Also, despite the growing body of evidence that school-based health services such as treatment of parasitic infections can be delivered at low cost and can contribute to improving children's general well-being and growth [11] [12], there is currently no national school-based parasitic infection control program in Nigeria [2].

Possibly, the lack of school-based control programs in many developing nations may have informed both the World Health Organization (WHO) and the American Centre for Disease Control (CDC) to have provided meaningful guidelines to promote health through the school system [13] [14]. One of the "core elements" of the guidelines proposed by the WHO is to conduct a situational analysis prior to intervention. Such an analysis provides a baseline of factors which are likely to impact on the health of the educators, learners, parents and the surrounding community [15]. A situation analysis helps "to better understand the needs, resources and conditions that are relevant to planning interventions" [13] [15].

Informed by these guidelines, we undertook a school-based health survey in Southern Nigeria. Part of the survey is primarily focused on parasitic infections. The objective of the survey was to examine the prevalence of parasitic infections and associated demographic factors among schooling adolescents with the aim of identifying factors that are relevant in the development of sustainable school-based intervention programs. To achieve our objective, we adopted the proposition of Moestue et al. [10] that the information given by students in a questionnaire is diagnostically reliable, so long as any under- or over-reporting is systematic and consistent, it could be used to identify schools where a health problem is common and where curative or preventive measures could be effectively directed. This notion has been well studied and validated for urinary schistosomiasis [16]-[18]. 


\section{Methods}

\subsection{Participants}

A total of 600 students from selected schools in Delta State Southern Nigeria, voluntarily participated in the study. Of the 600 students, incomplete data were removed and 585 were included in the analysis. Of these, $60.9 \%$ were male while $39.1 \%$ were female. The slight male predominance in the sample was because one of the schools is same sex (boys only) school. The average age of male participants was $15.0 \pm 2.0$ years while for female was $15.2 \pm 1.7$ years. The average age of all participants was $15.1 \pm 1.9$ years. The participants cut across both public and private schools and their parents were from varied educational and occupational backgrounds.

\subsection{Study Design, Data Collection and Survey Instrument}

The study design was a cross-sectional survey conducted at Delta State Southern Nigeria between July and August, 2013 using a self-administered questionnaire on general school health survey. The parasitic infections section was adapted from previous published study [16]. Socio-demographic and infection related information was collected with a structured questionnaire. The questionnaires were administered to students by trained field interviewers who explained how to fill out the instruments to the students. The questionnaire was completed anonymously. Prior to the study, participants were pre informed of the significance of the research and informed consent was obtained from those who agreed to participate in the study. Also, approval was obtained from the respective schools.

The questionnaire consisted of different sections. Demographic data; such as age, sex, setting of residence (geolocality) etc. 1) infection, 2) students were asked to report symptoms, and diseases experienced during the past twelve months. Also assessed were; highest level of parents' education: This is based on students self-reports and is divided into four levels: 1) not educated (illiterate); 2) primary school; 3) secondary education; 4) tertiary education; and parents' occupation: A more direct measure of the family economic situation was derived from a question reporting the occupation of the parents. This is based on students self-reports and responses were 1) none; 2) farming; 3) fishing; 4) business/trading; 5) civil servant; 6) others.

\subsection{Data Analysis}

The data from the survey was analyzed using STATISTICA version 12.0 and GraphPad Prism version 5.0. Chisquare test was used to compare differences among subjects by socio-demographic characteristics. Correlation analysis was to assess the agreement between the self-reported symptoms and diseases. Multivariate logistic regression was used to determine socio-demographic factors predictive of the outcome the presence of parasitic diseases (coded 1 for yes, and 0 for no). Missing values in the data set arising from items non-response were imputed using the random function in excel to avoid bias generated by list-wise deletion of subject with missing values from the statistical analysis. All reported $p$ values were made on the basis of two-tailed tests. Differences were considered statistically significant at $p$ value $<0.05$.

\section{Results}

\subsection{Prevalence of Self-Reported Parasitic Diseases by Socio-Demographic Factors}

The prevalence of the four infection diseases is shown in Table 1. The most prevalent parasitic diseases reported across the sample were malaria (46.9\%) and helminthiasis (27.7\%). The prevalence of malaria was higher among male students (60.5\%), urban dwellers (65.28\%), students attending public schools (51.6\%), students whose parents had higher education (68.4\%), and higher wealth status. The prevalence of helminthes infection was similar to that of malaria, being higher among male students (56.5\%), urban students (77.8\%), those attending public schools (50.6\%), those with parents of higher education status (65.7\%) and those whose parents are of higher economic status. Urinary schistosomiasis (27.7\%) and Diarrhea (19.7\%) infection were the least reported parasitic diseases among the student population.

\subsection{Associations between the Number of Parasitic Diseases and Socio-Demographic Characteristics}

Table 2 present the association between the numbers of self-reported parasitic diseases and socio-demographic 
Table 1. Prevalence of self-reported infectious diseases among students.

\begin{tabular}{|c|c|c|c|c|c|}
\hline \multirow{2}{*}{ Socio-demographics } & \multicolumn{4}{|c|}{ Self-reported diseases, N (\%) } & \multirow{2}{*}{$p$ value } \\
\hline & Malaria & Diarrhea & Urinary shistosomiasis & Intestinal Worms & \\
\hline All & $405(46.9)$ & 170(19.7) & $50(5.8)$ & $239(27.7)$ & \\
\hline \multicolumn{6}{|l|}{ Gender } \\
\hline Male & $245(60.5)$ & $85(50.0)$ & $20(40.0)$ & $135(56.5)$ & 0.0116 \\
\hline Female & 160(39.5) & $85(50.0)$ & $30(60.0)$ & $104(43.5)$ & \\
\hline \multicolumn{6}{|l|}{ Age (years) } \\
\hline$\leq 13$ & $93(23.0)$ & $27(15.9)$ & $8(16.0)$ & $47(19.7)$ & 0.1895 \\
\hline $14-17$ & 278(68.6) & $120(70.6)$ & $39(78.0)$ & 164(68.6) & \\
\hline$\geq 18$ & $34(8.4)$ & $23(13.5)$ & $3(6.0)$ & 28(11.7) & \\
\hline \multicolumn{6}{|l|}{ Geolocality } \\
\hline Rural & 141(34.8) & $17(10.0)$ & $3(6.0)$ & $53(22.2)$ & $<0.001$ \\
\hline Urban & $264(65.2)$ & 153(90.0) & $47(94.0)$ & 186(77.8) & \\
\hline \multicolumn{6}{|l|}{ School ownership } \\
\hline Public & 209(51.6) & $95(55.9)$ & $5(10.0)$ & 121(50.6) & $<0.001$ \\
\hline Private & 196(48.4) & $75(44.1)$ & $45(90.0)$ & $118(49.4)$ & \\
\hline \multicolumn{6}{|l|}{ Parent's level of edu* } \\
\hline illiterate & $9(2.2)$ & $7(4.1)$ & $3(6.0)$ & $10(4.2)$ & 0.6905 \\
\hline Primary & $25(6.1)$ & $12(7.1)$ & $6(12.0)$ & $15(6.3)$ & \\
\hline Secondary & $94(23.2)$ & $37(21.8)$ & $10(20.0)$ & $57(23.8)$ & \\
\hline Tertiary & $277(68.4)$ & 114(67.1) & $31(62.0)$ & $157(65.7)$ & \\
\hline \multicolumn{6}{|l|}{ Parent's occupation } \\
\hline Unemployed & $4(1.0)$ & $0(0.0)$ & $1(2.0)$ & $3(1.3)$ & 0.0972 \\
\hline Farmer & $16(3.9)$ & $12(7.1)$ & $1(2.0)$ & $15(6.3)$ & \\
\hline Fishing & $5(1.2)$ & $6(3.5)$ & $2(4.0)$ & $6(2.5)$ & \\
\hline Business/trader & 188(46.4) & $70(41.2)$ & $27(54.0)$ & $107(44.8)$ & \\
\hline Civil servant & $145(35.8)$ & $74(43.5)$ & $13(26.0)$ & $89(37.2)$ & \\
\hline Others & $47(11.6)$ & $8(4.7)$ & $6(12.0)$ & $19(7.9)$ & \\
\hline
\end{tabular}

*Education.

factors. Nearly a quarter (21.2\%) of the students reported not having any parasitic diseases, while (38.5\%) had one infectious diseases and about half (40.3\%) reported more than two infectious diseases. In the study sample, the number of parasitic diseases differed significantly by sex $(p=0.0344)$, age $(p=0.0483)$, geolocality $(p=$ $0.0001)$, school ownership ( $p=0.0012)$ and parents' occupation $(p=0.0199)$. The number of parasitic diseases did not differ significantly by level of parents' education $(p=0.4280)$ (Table 2$)$.

\subsection{Socio-Demographic Predictors of Presence of Parasitic Diseases}

Multivariate logistic regression analysis showed that attending privately owned school was significantly negatively associated with the presence of parasitic diseases $(p=0.0022)$. Although, parents' occupation and level of 
Table 2. Association between the number of diseases and socio-demographic characteristics.

\begin{tabular}{|c|c|c|c|c|}
\hline \multirow{2}{*}{ Socio-demographics } & \multicolumn{3}{|c|}{ Self-reported diseases, N (\%) } & \multirow{2}{*}{$p$ value } \\
\hline & 0 & 1 & $\geq 2$ & \\
\hline Total & $124(21.2)$ & $225(38.5)$ & 236(40.3) & \\
\hline \multicolumn{5}{|l|}{ Gender } \\
\hline Male & 78(62.9) & 149(66.2) & $129(54.7)$ & 0.0344 \\
\hline Female & $46(37.1)$ & $76(33.8)$ & $107(45.3)$ & \\
\hline \multicolumn{5}{|l|}{ Age (years) } \\
\hline$\leq 13$ & $26(21.0)$ & $58(25.8)$ & $50(21.2)$ & 0.0483 \\
\hline $14-17$ & $95(76.6)$ & $153(68.0)$ & 162(68.6) & \\
\hline$\geq 18$ & $3(2.4)$ & $14(6.2)$ & $24(10.2)$ & \\
\hline \multicolumn{5}{|l|}{ Geolocality } \\
\hline Rural & $40(32.3)$ & 111(49.3) & 49(20.8) & $<0.0001$ \\
\hline Urban & 84(67.7) & $114(50.7)$ & 187(79.2) & \\
\hline \multicolumn{5}{|l|}{ School ownership } \\
\hline Public & $39(31.5)$ & 102(45.3) & $122(51.7)$ & 0.0012 \\
\hline Private & 85(68.5) & $123(54.7)$ & $114(48.3)$ & \\
\hline \multicolumn{5}{|l|}{ Parent's level of edu* } \\
\hline illiterate & $1(0.8)$ & $3(1.3)$ & $9(3.8)$ & 0.4280 \\
\hline Primary & $9(7.3)$ & $16(7.1)$ & $15(6.4)$ & \\
\hline Secondary & $31(25.0)$ & $59(26.2)$ & 51(21.6) & \\
\hline Tertiary & 83(66.9) & $147(65.3)$ & 161(68.2) & \\
\hline \multicolumn{5}{|l|}{ Parent's occupation } \\
\hline unemployed & $0(0.0)$ & $4(1.8)$ & $2(0.8)$ & 0.0199 \\
\hline Farmer & $9(7.3)$ & $6(2.7)$ & $14(5.9)$ & \\
\hline Fishing & $2(1.6)$ & $2(0.9)$ & $5(2.2)$ & \\
\hline Business/trader & $60(48.4)$ & $110(48.9)$ & $106(44.9)$ & \\
\hline Civil servant & 29(23.4) & 73(32.4) & 89(37.8) & \\
\hline Others & 24(19.4) & 30(13.3) & $20(8.5)$ & \\
\hline
\end{tabular}

*Education.

education was negatively associated with presence of parasitic infections, the association was not significant (Table 3).

\subsection{Association between Self-Reported Symptoms and Parasitic Diseases}

Both Scatter plot and correlation analyses showed strong agreement between the self-reported symptoms and self-reported diseases $\left(R^{2}=0.93, r=0.98, p=0.0023\right)$, thus $93 \%$ of the self-reported symptoms could be explained by the diseases (Figure 1 ). 
Table 3. Estimate of multivariate logistic regression analysis for the outcome-presence of parasitic infection.

\begin{tabular}{|c|c|c|c|}
\hline Socio-demographics & Estimate & $95 \%$ CI & $\operatorname{Pr}(>|z|)$ \\
\hline \multicolumn{4}{|l|}{ Gender } \\
\hline Male & 1.00 & & - \\
\hline Female & -0.2942 & $0.46-1.20$ & 0.2302 \\
\hline \multicolumn{4}{|l|}{ Age (years) } \\
\hline$\leq 13$ & 1.00 & & - \\
\hline $14-17$ & 1.1169 & $0.81-11.51$ & 0.0989 \\
\hline$\geq 18$ & -0.1508 & $0.51-1.46$ & 0.5766 \\
\hline \multicolumn{4}{|l|}{ Geolocality } \\
\hline Rural & 1.00 & & - \\
\hline Urban & 0.353 & $0.76-2.66$ & 0.2699 \\
\hline \multicolumn{4}{|l|}{ School ownership } \\
\hline Public & 1.00 & & - \\
\hline Private & -0.9129 & $0.22-0.72$ & 0.0020 \\
\hline \multicolumn{4}{|l|}{ Parent's level of edu* } \\
\hline illiterate & 1.00 & & - \\
\hline Primary & -1.3538 & $0.03-2.39$ & 0.2328 \\
\hline Secondary & -1.5218 & $0.03-1.89$ & 0.1670 \\
\hline Tertiary & -1.6782 & $0.02-1.60$ & 0.1260 \\
\hline \multicolumn{4}{|l|}{ Parent's occupation } \\
\hline unemployed & 1.00 & & - \\
\hline Farmer & -15.3522 & 0.00 -Inf & 0.9792 \\
\hline Fishing & -14.9106 & 0.00-Inf & 0.9798 \\
\hline Business/trader & -14.4532 & 0.00-Inf & 0.9804 \\
\hline Civil servant & -14.1526 & 0.00 -Inf & 0.9808 \\
\hline Others & -14.9535 & 0.00-Inf & 0.9798 \\
\hline
\end{tabular}

*Education.

\section{Discussion}

Parasitic infections are considered a major health problem causing great suffering in the tropical and subtropical countries. Infected school children are often physically and mentally compromised by malnutrition, leading to cognitive deficits, learning disabilities and high school absenteeism [5]. Despite the health and cognitive implication associated with parasitic infections, there is no evidence of countrywide control program for parasitic infections in Nigeria as school health services are rudimentary [19] and currently funding for public health programs are skewed in favor of HIV/AIDS prevention [20]. This study is a situation analysis, focused on rapid assessment of the prevalence of parasitic infections among adolescent students based on self-reported diseases experienced with the past twelve months. The aim was to provide baseline information that would assist in the de- 


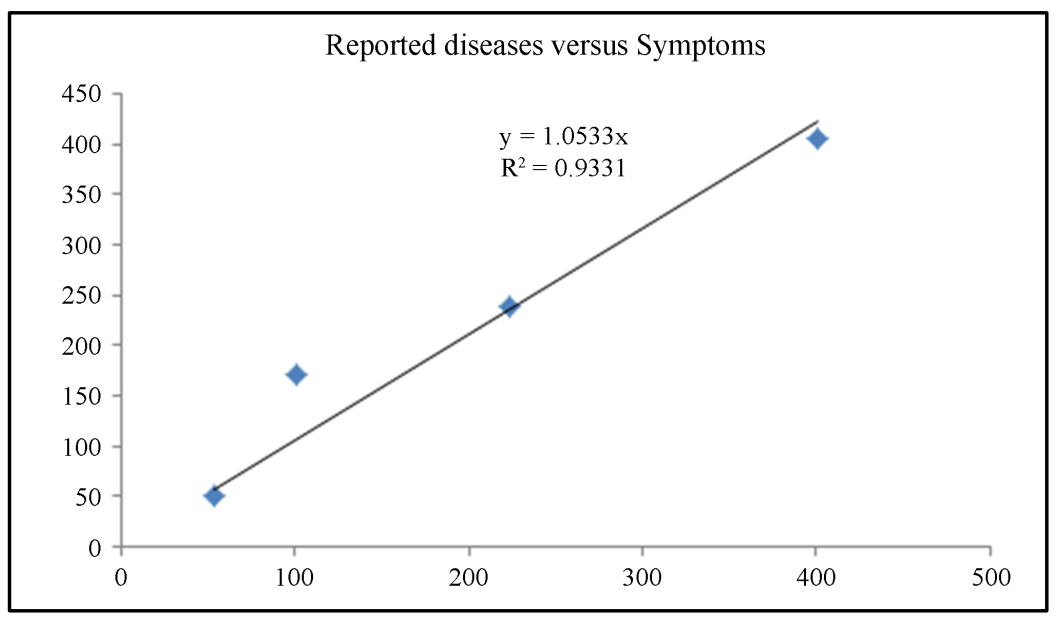

Figure 1. Relationship between self-reported diseases and reported symptoms.

signing an effective school-based intervention program that may incorporate laboratory diagnosis. A situation analysis helps "to better understand the needs, resources and conditions that are relevant to planning interventions [13].

The study revealed that about $40 \%$ of the studied population had one parasitic infection during the past twelve months and the most prevalent self-reported infections were malaria (46.9\%) and helminthic (27.7\%). This supports previous reports that the prevalence of parasitic infections are high in developing countries [2] [5]. The high rate of self-reported infection among the students indicates that much attention is required and the implication of this with respect to school absenteeism and performance are enormous, and this is a clear reflection of high rate of asymptomatic carriers in the community. The overall prevalence of $46.9 \%$ of malaria infection among the students in this region is not surprising as malaria is holoendemic in Nigeria, especially in the rural areas, but could be hyperendemic in urban areas [21] [22]. Morbidity and mortality due to malaria have been increasing due to deterioration in health system, growing drug and insecticide resistance, periodic changes in weather pattern, human migration and population displacement. In Nigeria, the epidemiology of malaria is relatively uniform throughout the year, but sometimes high at the rainy season [22]. Furthermore, the overall prevalence of $27.7 \%$ of helminthic infections is by far lower than the findings elsewhere in the southern Nigeria [5] [23]-[25]. This observation could be attributed to differences in study age groups, environmental contamination, degree of sanitation in the communities or that there may be an increased consciousness in health education and personal hygiene among our study population.

Result of this study indicates a relatively high prevalence of self-reported multiple infections ( $\geq 2$ infections) in the study area. It shows an overall prevalence of $40.3 \%$. Also, the number of parasitic diseases differed significantly by sex $(p=0.0344)$, age $(p=0.0483)$, geolocality $(p=0.0001)$, school ownership $(p=0.0012)$ and parents' occupation $(p=0.0199)$. It is particularly common in the tropical and sub-tropical countries where conditions of poor hygiene and sanitation co-exist with environmental factors favoring survival and spread of the extra-human parasitic stages. The high prevalence of multiple infections reported in this study is comparable to that of Raso et al. [26]. The suffering of multiple co-existing parasitic infections puts these young adolescents at an increased risk of parasitic infections. This may result in straining an already overburdened healthcare system. Therefore, there is need for comprehensive and coordinated interventions within the school health system targeting multiple infections that young students face. The study showed significant variations in self-reported number of parasitic infections by sex, age, and geolocality, school ownership and parents' occupation.

Other studies also found that male had higher prevalence of parasiticinfections compared to their female counterparts [5] [25] [27]. This calls for gender-specific interventions in addressing parasitic infections. These factors must be taken into consideration when designing control programs to ensure their effectiveness. It was also found that being female is negatively associated with presence of parasitic infection. This further confirms the higher prevalence of infections observed among males. This agrees in part with Rijal et al. [28] that females possess significantly higher levels of awareness about parasitic infections. Also being an urban dweller showed positive correlation with presence of parasitic infection. This is not an unexpected finding, given that most urban 
areas in tropical countries including Nigeria is overcrowded and associated with poor sanitary conditions. Parasitic infections persist and flourish wherever poverty, inadequate sanitation and overcrowding are entrenched [28]. The association between age group and presence of infections showed an interesting pattern. Age $(\geq 18$ years) showed a negative association while $14-17$ years on the other hand showed a positive correlation. A possible explanation to this could be that the student within the age group $\geq 18$, may have higher level of awareness about parasitic infections and practices more personal hygiene compared to younger students thus are less exposed to parasitic infections. That we found significant negative relationship between presence of infection and students attending private school possibly suggests that privately owned schools have better sanitation conditions in and around schools compared to public school or higher economic status of most students' parents in the private schools may be the underling factors. The former concur with the report of Ekpo et al. [2] that the water and sanitary conditions were poorer in government-owned schools than in the private schools.

\section{Strength and Limitation}

This study provide a firm basis on which to monitor and evaluate parasitic infections patterns among schooling children and adolescents in Nigeria and other Africa nations with similar settings. Rapid approach to evaluating health situation prior to intervention is an important first step in responding to the need to reduce the burden of parasitic infections in schools and community at large. We observed association between the number of parasitic infections and demographic characteristics. Furthermore, the multivariate logistic regression analysis though revealed the correlation of infections with demographic factors, only school ownership proved to be a significant predictor of parasitic infection among this population thus suggesting that the correlates of parasitic infections may differ from those of multiple infections. These findings heighten the need for a better understanding of the underlying synergetic factors that could be associated with parasitic infection among student population in Nigeria. Also, there is need to understand how these patterns are evolving over time, the implications of those changes for students and the communities, and patterns of school health use over time. Rapid assessment and laboratory follow-up surveys are therefore needed to monitor trends and patterns over time.

However, the results of this study must be interpreted with caution as there are several limitations. First, the self-report of parasitic infections within the past twelve months should be treated with caution. It is possible that self-reports of infections may be subject to social desirability biases; thus, the findings may be underestimated. Self-reported assessments of infection remain the most feasible and affordable instruments for global surveillance though, it will be beneficial to validate the self-reported infections with laboratory investigation to reveal the true picture of infections among student.

Second, the possibility of recall bias cannot be rule out. Considering the likelihood that detail of the infection could be lost due to memory-decay, and/or "tele-scoping" resulting in the inclusion of infection that occurred outside the recall period. There is a need for studies to evaluate the reliability of recall over different periods to see if the self-reported prevalence of infection is proportional. Studies have shown that reporting errors may be related to the length of the recall period and the severity of the disease [29]. Nmor et al. [30] proposed that a short recall period of 6 months should minimize error due to recall bias. Despite these limitations, our study give important insight into socio-demographic factors associated with multiple parasitic infections among young schooling adolescents in Nigeria.

\section{Conclusion}

This study provides useful information that can aid decision making and resource allocation for improving school health. For instance, the association between occupation and number of parasitic infections suggests that parents with better economic status could have more resources to take care of their children and thereby reduce the risk of multiple parasitic diseases. The study confirms the view that parasitic infections should not be considered in isolation from one another as they may co-exist and may also have synergistic effects on disease risk. Thus, comprehensive school-health promotion interventions should not only be tailored for specific demographic groups but also focus on addressing multiple parasitic disease risk factors.

\section{Competing Interests}

The authors have no competing interests to declare. 


\section{Authors' Contributions}

JCN was the principal investigator and was responsible for study design, data acquisition, analysis and interpretation, and drafting of the manuscript. PO was involved in data collection. JN assisted with data analysis and drafting of the manuscript. KG, JT and FD participated in the study design.

\section{Acknowledgements}

The authors wish to acknowledge the cooperation of the students who participated in the study. This research was supported by fund for scientific research from the Osaka Kyoiku University. The funders had no role in the study design, data collection and analysis, decision to publish, or preparation of the manuscript.

\section{References}

[1] Montresor, A., Crompton, D.W.T., Hall, A., Bundy, D.A.P. and Savioli, L. (1998) Guidelines for the Evaluation of Soil Transmitted Helminthiasis and Schistosomiasis at Community Level. World Health Organization, Geneva, WHO/CTC/ SIP/98.

[2] Ekpo, U.F., Odoemene, S.N., Mafiana, C.F. and Sam-Wobo, S.O. (2008) Helminthiasis and Hygiene Conditions of Schools in Ikenne, Ogun State, Nigeria. PLoSNegleted Tropical Diseases, 2, e146. http://dx.doi.org/10.1371/journal.pntd.0000146

[3] World Health Organization (2009) WHO World Malaria Report. Geneva.

[4] Furness, B.W., Beach, M.J. and Roberts, J.M. (2000) Giardiasis Surveillance-United States, 1992-1997. Morbidity and Mortality Weekly Report (MMWR) CDC Surveillance Summaries, 49, 1-13.

[5] Nmor, J.C., Onojafe, J.O. and Omu, B.A. (2009) Anthropogenic Indices of Soil-Transmitted Helminthiasis among Children in Delta State, Southern Nigeria. Iranian Journal of Public Health, 38, 31-38.

[6] Girum, T. (2005) The Prevalence of Intestine Helminthic Infections and Associated Risk Factors among School Children in Babile Town, Eastern Ethiopia. Ethiopian Journal of Health Development, 19, 140-147.

[7] Yakubu, N., Musa, G. and Yakubu, S.E. (2003) Seasonal Changes in the Distribution and Infection Rate of Schistosoma Intermediate Hosts in River Kubanni and Its Tributaries. Bio Research Communication, 15, 207-214.

[8] Gelaw, A., Anagaw, B., Nigussie, B., Silesh, B., Yirga, A., Alem, M., Endris, M. and Gelaw, B. (2013) Prevalence of Intestinal Parasitic Infections and Risk Factors among Schoolchildren at the University of Gondar Community School, Northwest Ethiopia: A Cross-Sectional Study. BMC Public Health, 13, 304. http://dx.doi.org/10.1186/1471-2458-13-304

[9] Goodburn, E.A. and Ross, D.A. (2000) Young People’s Health in Developing Countries: A Neglected Problem and Opportunity. Health Policy and Planning, 15, 137-144. http://dx.doi.org/10.1093/heapol/15.2.137

[10] Moestue, H., Mahumane, B., Zacher, A., Issae, W., Kihamia, C.M., Wen, S.T., Adjei, S., Bundy, D.A. and Hall, A. (2003) Ill-Health Reported by Schoolchildren during Questionnaire Surveys in Ghana, Mozambique and Tanzania. Tropical Medicine and International Health, 8, 967-974. http://dx.doi.org/10.1046/j.1360-2276.2003.01113.x

[11] Stoltzfus, R.J., Albonico, M., Chwaya, H.M., Tielsch, J.M., Schulze, K.J. and Savioli, L. (1998) Effects of the Zanzibar School-Based Deworming Program on Iron Status of Children. American Journal of Clinical Nutrition, 68, 179-186.

[12] Ekundayo, J.O., Aliyu, H.M. and Jolly, E.P. (2007) A Review of Intestinal Helminthiasis in Nigeria and the Need for School-Based Intervention. Journal of Rural and Tropical Public Health, 6, 33-39.

[13] World Health Organization (2008) 2008-2013 Action Plan for the Global Strategy for the Prevention and Control of Non-Communicable Diseases. WHO, Geneva.

[14] Centers for Disease Control and Prevention (1997) Guidelines for School Health Programs to Promote Lifelong Healthy Eating. Journal of School Health, 67, 9-26. http://dx.doi.org/10.1111/j.1746-1561.1997.tb06289.x

[15] De Villiers, A., Steyn, N.P., Draper, C.E., Fourie, J.M., Barkhuizen, G., Lombard, C.J., Dalais, L., Abrahams, Z. and Lambert, E.V. (2012) "HealthKick": Formative Assessment of the Health Environment in Low-Resource Primary Schools in the Western Cape Province of South Africa. BMC Public Health, 12, 794.

[16] Ekpo, U.F. and Mafiana, C.F. (2005) Epidemiological Studies of Urinary Schistosomiasis in Ogun State, Nigeria: Identification of High-Risk Communities. Nigerian Journal of Parasitology, 25, 111-119.

[17] Okon, O., Ememayom, A. and Opara, K. (2009) Reliability of Self-Reported Blood in Urine for Diagnosis of Schistosoma haematobium in a Community in South-Eastern Nigeria. The Internet Journal of Epidemiology, 7, 2.

[18] Clements, A.C., Barnett, A.G., Nyandindi, U., Lwambo, N.J., Kihamia, C.M. and Blair, L. (2008) Age and Gender Ef- 
fects in Self-Reported Urinary Schistosomiasis in Tanzania. Tropical Medicine and International Health, 13, 713-721. http://dx.doi.org/10.1111/j.1365-3156.2008.02048.x

[19] Ola, J.A. and Oyeledun, B. (1999) School Health in Nigeria: National Strategies. In: World Health Organization (Ed.), Improving Health through Schools: National and International Strategies. WHO, Geneva, 81-84.

[20] Ekundayo, J.O., Aliyu, H.M. and Jolly, E.P. (2007) A Review of Intestinal Helminthiasis in Nigeria and the Need for School-Based Intervention. Journal of Rural and Tropical Public Health, 6, 33-39.

[21] Onwujekwe, O., Chima, R. and Okonkwo, P. (2000) Economic Burden of Malaria Illness on Households versus That of All Other Illness Episodes: A Study in Five Malaria Holo-Endemic Nigerian Communities. Health Policy, 54, 143159. http://dx.doi.org/10.1016/S0168-8510(00)00105-6

[22] Omolade, O.O. and Adejoke, C.I. (2010) The Malaria Situation, Perception of Cause and Treatment in a Nigerian University. Journal of Medicine and Medical Sciences, 1, 213-222.

[23] Adefioye, O.A., Efunshile, A.M., Ojurongbe, O., kindele, A.A., Adewuyi, I.K., Bolaji, O.S., Adedokun, S.A. and Adeyeba, A.O. (2011) Intestinal Helminthiasis among School Children in Ilie, Osun State, Southwest, Nigeria. Sierra Leone Journal of Biomedical Research, 3, 43-48. http://dx.doi.org/10.4314/sljbr.v3i1.66651

[24] Agbolade, O.M., Akinboye, D.O. and Awolaja, A. (2004) Intestinal Helminthiasis and Urinary Schistosomiasis in Some Villages of Liebu North, Ogun State, Nigeria. African Journal of Biotechnology, 3, 206-209.

[25] Oyewole, F., Ariyo, F., Oyibo, W.A., Sanyadu, A., Faweya, T. and Monye, P. (2007) Helminthic Reduction with Albendazole among Children in Riverine Communities of Nigeria. Journal of Rural Tropical Public Health, 6, 6-10.

[26] Raso, G., Luginbühl, A., Adjoua, C.A., Tian-Bi, N.T., Silué, K.D., Matthys, B., Vounatsou, P., Wang, Y., Dumas, M., Holmes, E., Singer, B.H., Tanner, M., N’Goran, E.K. and Utzinger, J. (2004) Multiple Parasite Infections and Their Relationship to Self-Reported Morbidity in a Community of Rural Côte d'Ivoire. International Journal of Epidemiology, 33, 1092-1102. http://dx.doi.org/10.1093/ije/dyh241

[27] Ukpai, O.M. and Ugwu, C.D. (2003) The Prevalence of Gastro-Intestinal Tract Parasites in Primary School Children in Ikwuano Local Government Area of Abia State, Nigeria. The Nigerian Journal of Parasitology, 24, 129-136.

[28] Rijal, B., Oda, Y., Basnet, R., Parajuli, K., Gurung, C.K. and Sherchand, J.B. (2001) Gender Variations in the Prevalence of Parasitic Infections and the Level of Awareness in Adolescents in Rural Nepal. Southeast Asian Journal of Tropical Medicine and Public Health, 32, 575-580.

[29] Ramakrishnan, R., Rao, T.V., Sundaramoorthy, L. and Joshua, V. (1999) Magnitude of Recall Bias in the Estimation of Immunization Coverage and Its Determinants. Indian Pediatrics, 36, 881-885.

[30] Nmor, J.C., Nwaka, K.H., Goto, K., Toyosawa, J. and Fujita, D. (2013) High Rate of Injuries among Students in Southern Nigeria: An Urgent Call to Action. Health, 5, 1965-1975. http://dx.doi.org/10.4236/health.2013.512266 